\title{
Impact of Online Education on Student Learning during the Pandemic
}

\author{
${ }^{*}$ H Kohli', D Wampole', A Kohli ${ }^{2}$ \\ 1School of Social Work University of Southern Maine, Portland, Maine, 04105, United States of America \\ 2School of Business, University of Southern Maine, Portland, Maine, 04105, United States of America
}

\begin{tabular}{|c|c|}
\hline Article Info & ABSTRACT \\
\hline Article history: & \multirow{11}{*}{$\begin{array}{l}\text { Using qualitative exploratory research, we documented the } \\
\text { experiences of } 90 \text { undergraduate and graduate students on how online } \\
\text { education was affecting their learning during the pandemic. Data was } \\
\text { collected from School of Social Work students at a northeastern publi } \\
\text { university in the United States. The participants were unsatisfied with } \\
\text { the unexpected disruption to online education. However, they had } \\
\text { adjusted to digital learning and stated that they would rather have } \\
\text { subpar education than put themselves and others in danger due to } \\
\text { COVID-19. The major challenges that the students encountered are: (a) } \\
\text { struggle with online education, (b) difficulty connecting with } \\
\text { instructors, (c) lack of motivation, (d) losses, (e) difficulty accessing } \\
\text { other learning resources, and (f) unsafe/inaccessible home } \\
\text { environment. Recommendations are provided for instructors and } \\
\text { administrators to support students in these challenging times. }\end{array}$} \\
\hline Received May 19, 2021 & \\
\hline Revised August 3, 2021 & \\
\hline Accepted September 8, 2021 & \\
\hline Available Online September 9, 2021 & \\
\hline Keywords: & \\
\hline COVID-19 & \\
\hline Higher education & \\
\hline $\begin{array}{l}\text { Learning } \\
\text { Online education }\end{array}$ & \\
\hline Students & \\
\hline & \\
\hline
\end{tabular}

\section{INTRODUCTION}

Our lives have been upended in ways that are incomprehensible, not only because of the confirmed number of infections at a staggering 119 million and deaths related to COVID-19 passing over 2.6 million globally, but also because of the wide-ranging consequences the pandemic has had on our collective mental, emotional, and financial wellbeing (World Health Organization, 2021). The shutdowns imposed to control the novel coronavirus and avert a global health crisis necessitated a hasty but nimble transition to virtual education for all - from K-12 schools to the institutions of higher education. The past year has been extremely stressful and disorienting for students and instructors alike as they are learning to adapt to this sudden shift to remote instruction. Numerous research studies have documented the adaptation to teaching and learning (Al-Okaily, Alqudah, Matar, Lutfi, \& Taamneh, 2020; Evans, 2020; Griffiths, 2020; Jena, 2020; Karademir, Yaman, \& Saatçioğlu, 2020; Mladenova, Kalmukov, \& Valova, 2020); and student vulnerabilities (Aucejo, French, Araya, \& Zafar, 2020; Chen, Liang, Peng, Li, Chen, Tang, \& Zhao, 2020; Cohen, Hoyt, \& Dull, 2020; Palgi et al., 2020; Shahzad, Hassan, Aremu, Hussain, \& Lodhi, 2020). Our research builds on this knowledge by documenting the experiences of undergraduate and graduate students on how online education is affecting their learning during the pandemic in a School of Social Work at a northeastern public university in the United States.

\section{LITERATURE REVIEW}

\section{Adaptation to Teaching and Learning}

With the uncontrolled COVID-19 surge, universities worldwide have been compelled to migrate to some form of remote instruction. Research is emerging as academia is responding to this sudden unexpected transition to eLearning globally (Al-Okaily, et al., 2020; Hasan \& Bao, 2020; Evans, 2020; Griffiths, 2020; Jena, 2020; Karademir et al., 2020; Mladenova et al., 2020; Toquero, 2020). Even though online and blended learning has been mainstreamed for several decades, 
continuing professional development resources needed to make flexible, interactive, creative, and fun online courses are dwindling (Griffiths, 2020). Many studies are documenting the acceptance of students to the online medium (Al-Okaily et al., 2020; Ana, Minghat, Purnawarman, Saripudin, Muktiarni, Dwiyanti, \& Mustakim, 2020; de Boer, 2021). University students' acceptance of eLearning in Jordan was positively correlated with subjective ease, perceived ease of use, and perceived usefulness (Al-Okaily et al., 2020). In Malaysia and Indonesia, e-learning was positively accepted by the students - more than half of the participants were well prepared for the unforeseen transition to remote learning (Ana et al., 2020). Student enrollment and satisfaction in online courses in Dutch universities saw an uptick, with more students completing online courses as they were not able to find suitable learning opportunities for a gap year (de Boer, 2021).

Even though some students favor online learning, research is indicating that students are having a difficult time adjusting to remote instruction during the pandemic particularly in the context of following guidelines, struggle with deadlines, lack of interest, and expectation for speedy replies from instructors at odd hours (Mladenova et al., 2020). Additionally, although online learning allowed students to continue on their educational paths, it is disadvantaging students who are financially devastated, have unstable internet connection, lack self-discipline, and are socially isolated (Ana et al., 2020; Kapasia, et al., 2020). Infrastructure access and reliability were big hindrances in Turkey, which were furthermore exacerbated by anxiety, stress, and uncertainty caused by the pandemic on university employees, students, and their families (Karademir et al., 2020).

Lack of information and digital competence in students is leading to gaps in assessment and inability to effectively communicate, despite mastery of technological tools and extensive use of mobile devices (Sales, Cuevas-Cerveró, \& Gómez-Hernández, 2020). Students at a medical school in India were frustrated with online (Zoom-based) flipped classrooms and were requesting a reduction in the number of class sessions to keep up with the space and speed of work online (Roy, Ray, Saha, \& Ghosal, 2020). Even with access to good quality internet and technology savviness, for some students face to face classes were the preferred modality (Adnan \& Anwar, 2020; Roy et al., 2020). Hence, one can argue that neither a fully online nor a complete return to face-to-face instruction will be desirable post-pandemic requiring universities worldwide to rethink higher education modalities (Eringfeld, 2021).

\section{Student Vulnerabilities During the Pandemic}

Emerging research is magnifying the mental health struggles that are negatively impacting the emotional, psychological, and social well-being of college students worldwide as they navigate online learning during the pandemic (Aucejo, et al., 2020; Chen, et al., 2020; Hasan \& Bao, 2020; Kapasia, et al., 2020; Palgi et al., 2020; Shahzad, et al., 2020; Son et al., 2020). About 7.7\% of university students in China manifested depressive symptoms during the COVID-19 pandemic, which was higher than the depressive symptoms observed in the general population at about $4.3 \%$ during the same time (Chen et al., 2020). Cao and colleagues reported that an astounding $24.9 \%$ of college students in China were experiencing anxiety since the onset of the pandemic. Economic distress, life trauma, academic delays, and exposure to the novel coronavirus in their family unit were positively associated with anxiety (Cao et al., 2020; Wang et al., 2020).

University students in Bangladesh were reported to have significant psychological distress due to fear of the academic year (Hasan \& Bao, 2020). A study of Indian students corroborated an increase in suffering from stress, depression, and anxiety during the pandemic - about $42 \%$ of the 232 students surveyed were facing mental health stressors (Kapasia, et al., 2020). Loneliness and isolation imposed by the quarantine were identified as key risk factors for depression and anxiety (Palgi, et al., 2020). High levels of anxiety and stress have been documented in college students in the United States during the pandemic (Hoyt et al., 2020; Rudenstine, McNeal, Schulder, Ettman, Hernandez, Gvozdieva, \& Galea, 2020). Multiple stressors have been identified that have increased anxiety, depression, and stress within college students as they grapple with remote learning during the pandemic - income disparities, health disparities, fear of loss, 
concentration reduction, sleep disruption, social isolation, and academic failures (Hoyt, Cohen, Dull, Castro, \& Yazdani, 2020; Rudenstine, et al., 2020; Son, et al., 2020; Wang et al, 2020).

\section{RESEARCH METHOD}

The research question for this qualitative exploratory research was: "How are the current social distancing practices and resulting remote learning affecting your learning during the pandemic?" Ninety students at the School of Social Work in a northeastern United States public university responded to this question. This research was approved by the University's Office of Research Compliance and the respondents were guaranteed anonymity. Participation in the study was voluntary and \$5 Amazon gift cards were provided to the participants. We employed a qualitative systematic content analysis (SCA) approach as defined by Krippendorff (2019) and Schreier (2012). SCA is an appropriate design for analyzing data to excavate meaning and key themes. We will now identify the trustworthiness procedures, outline the inclusion criteria, and explain coding.

\section{Trustworthiness}

We employed strategies to ensure rigor and soundness by employing an interdisciplinary research team. All the researchers served as a check and balance for all research activities, including research design, sample selection, and data analysis (Denzin \& Lincoln, 2011). We worked collaboratively and utilized a consensus coding process. Additionally, we engaged in ongoing reflexive journaling and team discussion to reduce the impact of our own assumptions on the research.

\section{Sampling Procedures and Inclusion Criteria}

A convenient sampling strategy was employed, and the unit of analysis was data collected from students enrolled in the School of Social Work in a northeastern public university. All the undergraduate and graduate students enrolled in the Spring 2020 semester were invited to participate in this web-based survey, and the data were collected online using the Qualtrics Survey Software during a four-month period (March 2020 - June 2020). We utilized Krippendorff's (2019) four-step process of unit identification, sampling, coding, and reducing. All raw data was cleaned, and the transcripts were coded and analyzed. After careful and repeated examination of the transcripts, categories and subcategories of analysis were developed and defined. The categories of themes evolved during the analysis as more patterns, variations, and concepts were identified. Analysis was further accomplished by identifying the themes that emerged most frequently across the transcripts.

\section{Participant Profile}

The sample consisted of ninety undergraduate $(40 \%)$ and graduate $(60 \%)$ social work students enrolled in a Council on Social Work Education (CSWE) accredited School of Social Work in a northeastern public university in the United States. The mean age of the group was 29 (SD 9.3), with a range from 18 to 59 years, which is reflective of the university's age diversity. The group had around 18 years of education on average (SD 2.4), and a mean of 8.2 years of professional social work employment, with a range of 0 - 35 years (SD 7.8). About $90 \%$ of participants identified as female, $7 \%$ male, and $1 \%$ each identified as transgender female, gender variant/nonconforming, and agender. Nearly $91 \%$ of the respondents identified as White/European American, 5\% as Black/African American, and 4\% Hispanic/Latinx. About half of the participants were single, $28 \%$ were married (or in a civil partnership), $18 \%$ were cohabitating with a partner, and $2 \%$ each identified as divorced and widowed; and only $22 \%$ of students reported having a disability. The sample was predominantly heterosexual (75\%), 13\% identified themselves as bisexual, $8 \%$ queer/gay/lesbian, 2\% pansexual, and 2\% questioning/unsure. Around $9 \%$ of responding students identified themselves as Republican, 31\% as Independent, and $60 \%$ as Democrats. Approximately $32 \%$ of the respondents lived in urban areas, $26 \%$ resided 
in suburban areas, and $42 \%$ were from rural areas. More than half of the respondents $(60 \%)$ shared they were not religious and identified as either atheists, agnostics, or non-religious. About $26 \%$ identified as Christians, 4\% Jewish, 1\% Buddhist, and 9\% shared they ascribed to the other category (non-denominational spirituality, belief in higher power, and witchcraft). About $36 \%$ of students were leaning towards both non-spiritual and very-spiritual, with about $28 \%$ at the middle of the continuum from 1-7, where 1 reflected on-spiritual and 7 reflected very-spiritual.

\section{RESULTS AND DISCUSSION}

The majority of the respondents shared that sudden shift to online learning had a significant impact on their learning as documented by one participant, "My learning at (this institution) feels very disorganized sometimes, remote learning in a new place doesn't make for a smooth transition". Six major themes emerged on the significant challenges students faced during the shift to remote instruction that will be discussed next: (a) struggle with online education, (b) difficulty connecting with some instructors, (c) lack of motivation, (d) losses, (e) difficulty accessing other learning resources, and (f) unsafe/inaccessible home environment.

\section{Struggle with Online Education}

Struggle with online education was a major theme and one participant reported, "Moving to online classes has been terrible. I feel like we're not really in class anymore, just scrambling to finish assignments". Another student discussed, "[Online] learning feels 'flatter', not as full and effective". Three sub-themes were identified regarding participants' struggle with online education: (a) discomfort with remote/online learning, (b) reduced engagement in online environment, and (c) lack of rigor.

Discomfort with remote/online education. Discomfort with distance education was elucidated by all the respondents. They all found the shift too hard to adjust to, and emotions ranged from "difficult transition", "terrible", "hard", "hurts", "tough", and "hate". One student reflected, "The social distancing practices have made my learning slightly difficult as I am a hands-on learner and I find it hard to learn things online and not in the classroom". Another respondent corroborated, "I feel I am learning much less now than in class. Discussions are a major part of social work learning for me, so not having these makes the information not stick with me as well." Still another participant deliberated, "I hate online learning. Online learning without in-person discussions just doesn't do it for me and I know that the quality of my learning has decreased because of this". This sentiment was shared consistently, "It's been a bummer missing out on class time, as I learn best in class rather than online". The reasons for the disconcert were: (a) difficulty staying on task and focus; (b) difficulty time remembering deadlines and assignments for online classes, and (c) strains and headaches caused by overuse of electronics.

Reduced engagement in online classes. Another sub-theme that emerged from the data was the students' perception of reduced engagement in online learning. One student relayed, "It's hard to practice social work when you aren't able to be social". Visual and conversational learners found it difficult to absorb as much information online as they could in a classroom setting. One student spoke that, "...it can sometimes feel like I am teaching myself on subjects that I could use more guidance on". Furthermore, students perceived that online discussion boards were not affording the same opportunity and learning as passionate in-person discussions. One student shared, "It's awkward to have class discussions but we're figuring it out". Another student reflected, "I hate distance learning. I think it squanders the ability to have deep, well-rounded conversations about the subject matter". The sentiment that online discussion can never compare to face-to-face discussions was rampant as noted here, "I miss in-person class discussions. Online discussion boards have just never come close to what it's like to hear from professors and classmates in person".

Additionally, students discussed that they were finding taking some courses i.e., Social Work Practice and Research to be difficult online. Students' narratives regarding this are reflected here - "I'm missing out learning how to do individual therapy in person"; "I'm pretty disappointed 
about this one [practice course] because I want to use these techniques and I feel that I haven't received much other hands-on training in clinical therapeutic approaches", and "I'm taking a very hands-on elective course this semester and doing this by Zoom has greatly inhibited the learning". Finally, the students shared their frustrations and difficulties in completing group work online via Zoom and one student said, "It is difficult to conduct group projects over Zoom" and another stated, "It has affected group work in a lot of ways, making it more stressful". For classes that were meeting synchronously via Zoom, a few students shared their disdain regarding the overuse of Zoom. One student raised this concern, "I feel like I'm learning a whole lot less by doing all of this online".

Lack of rigor. Students were disappointed that their online courses were lacking rigor. As one elucidated here, "My online classes seem to be far less rigorous, and I don't feel challenged by them at all. While I'm grateful for the compassion my instructors are showing us as we navigate this situation, it all feels a little bit pointless. Like we're treading water until the end of the semester". In addition, students were unhappy with many instructors shifting their discussions from required readings to impacts of COVID-19. A student sentiment further elaborates on this, "...class became a Zoom call for peers to discuss the impacts of covid19 on their lives, and learning any planned class content went out the window. So the end of the semester was not a period of learning". And, another student echoed, "My classes completely changed to analyzing the COVID-19 response in (our state)".

\section{Difficulty Connecting with Instructors}

Participants shared concerns regarding access to their instructors as documented in these quotes: "It has been a bit difficult to communicate with some professors"; "I honestly don't think that I learned anything new this semester because the professors gave up"; and "It's really hard for me to communicate what I need to my professor online".

\section{Lack of Motivation}

The lack of motivation to continue with schoolwork due to the increased uncertainty and stress caused by the pandemic was another recurrent theme. One participant eloquently stated

"I'm finding the current global crisis to be negatively affecting my ability to concentrate and to find the motivation necessary to complete the tasks required of me by my professors. What's the point of writing a paper when people I know are sick or dying?"

Another participant discussed, "I'm finding it hard to motivate [myself] to do school work when there is such a global disaster happening outside". Still another participant shared, "My mind is preoccupied with what the world is going through, and it makes school and homework seem trivial at times". And one respondent confronted us to not forget about "...the challenges people of color face in attending a predominantly white institution".

Lack of motivation resulted in procrastination, and lack of accountability at home further disengaged some of the students from the course work. One respondent noted, "I procrastinate a lot, so I am struggling with not having the motivation to do some of my work. With attending classes in person there is this feeling of accountability that I don't have when I am home". Moreover, students found it difficult to adapt to remote learning due to lack of focus at home during the quarantine. One student reflected, "I am having a difficult time focusing being stuck at home all day, not being able to study or do work at (an)other place".

\section{Losses}

Losses due to missing out on the graduation celebration and loss of classroom and community support, along with the internship experience being cut short was another theme. For the graduating undergraduate and graduate students, missing out on the commencement celebration was identified as a huge loss. One participant shared, "We never had a proper goodbye and we 
will not have our celebration at graduation. It is frustrating, saddening, and confusing all at once. Is this really happening? This isn't a movie"? Missing out on graduation seems to have cut short the end of their learning experience, and one student reflected, "I feel like I didn't get a true sense of closure".

Furthermore, many students shared their challenges with the disruption in the internship/fieldwork experience. Struggles were documented by students who were applying for fieldwork experience for the next academic year, as elaborated by one participant, "It has made it more challenging to get a field work interview done and get accepted for field work due to bad internet connections". The respondents spoke of frustration, anger, disappointment, regret, and huge loss due to missing out on the last two months of their internship. One student voiced, "Studying theoretical applications of concepts is helpful, but actually working with clients face to face is a much more powerful teacher. I regret that I'm not able to continue experiencing that at this time because of the pandemic". Another student discussed, "I, like all students, was unable to finish my fieldwork in person. This feels very strange and unfinished especially because the agency isn't contacting me at all. There is some guilt that I left unintentionally without saying goodbye". Students noted how this cut short their own learning, "I was disappointed I couldn't finish my internship on site. I had many ideas of techniques and skills I wanted to try".

Missing out on the classroom and community support from peers and professors due to the transition to online learning was another major loss and challenge that the students had to contend with. The abrupt transition with social distancing in all arenas of their life exacerbated the loss and resulting stress. One participant stated, "I was highly active in my community, which all ended within a day. I also miss my community". Another student reported, "Being unable to see classmates and professors has been hard, especially since we didn't see this coming". Students missed classroom teaching and learning as it helped build community and trust, as documented by one respondent, "I miss the discussions, the laughter, and the comradery that we had", and another shared, "I miss the dialogue that happens in class and feeling connected to other social work students".

The sudden disruption of classroom teaching resulted in isolation for many students that further negatively impacted their school work as chronicled by one respondent, "I feel isolated at times and a lack of connection with my professors and peers has impacted my motivation to complete work". The isolation made the academic journey difficult, as observed by one student, "It just felt difficult (and still continues to feel difficult) not being with my peers. I am a person who thrives off routines and in-person contact and both were taken away. It definitely makes me feel more isolated". Another student echoed, "In a lot of ways, [the pandemic] has stripped me of my socialization around schooling". For students who were new to the region, this sense of isolation during the pandemic created an emotional turmoil as shared by one student,

"I have very few friends so appreciate the class time I got to spend with my classmates. That does not necessarily affect my learning but does my emotional state and at the end of the day it is all connected".

Another student summarized, "The installation of remote learning comes with feelings of loss as I am not able to be with my cohort".

\section{Difficulty Accessing Other Learning Resources}

Respondents brought to the forefront difficulties they faced accessing other learning resources when the university transitioned into online education. One student complained, "My resources to learn have been distanced, changed, become harder to get to, or completely disintegrated since the transition". Key services that the students noted they were having difficulty or were finding ineffective online were - tutoring and library as a physical space for learning. We need to focus on the needs of the vulnerable students as we engage in educational planning post-pandemic. 


\section{Unsafe/Inaccessible Home Environment}

Participants disclosed that the pandemic had forced them to continue living in an unsafe environment or one that is unfit for productive learning due to disabilities. One participant disclosed struggles they have to contend with while living in an unsafe home environment,

"I live with a family member who is a substance abuser and I am more focused on locking my door at night and accounting for my things rather than sit and learn. Normally I can escape to a coffee shop or my partner's home but now I am stuck, which is extremely anxiety-producing".

Another participant stressed, "I have a harder time focusing from home". Still another participant with a disability contended, "My entire education was made inaccessible due to my [disability]".

\section{Discussion}

The pandemic has strained university instructors and students personally and professionally as they undertake the daunting task of engaging in the learning as their own support systems disintegrate as everyday life is upended during the pandemic (de Boer, 2021; Evans, 2020). All participants reported struggles with online education - the transition to remote learning was difficult for all the participants. Even though they were unsatisfied with the unexpected disruption to their learning due to the pandemic, they had adjusted to digital learning. The respondents reflected that they would rather have a disruptive and subpar education in the times of the pandemic than be the carriers and get sick or worse still make someone in their own family and community sick. Educators and administrators need to be aware of the struggles that students encountered during this transition due to discomfort with remote/online learning, reduced engagement in online classes, and lack of rigor in coursework. Prior research has highlighted that limited institutional resources, internet unreliability, and social impediments on learners, are tremendously testing the capacity of academic institutions to deliver basic equitable access to education to all (Crawford et al., 2020; Peters, et al., 2020; Tesar, 2020). Even though the participants in this research did not face any technological difficulties, educators need to grapple with the students' distress adjusting to a completely online learning environment. Learning online leads to reduced rigor and engagement if the curriculum is not well planned. Faculty need to contend with these critical questions as they work on developing their courses for online environment: How can rigor be ensured in the coming semesters? While it can be expected that rigor loosened in the early onset of the pandemic when universities underwent drastic COVIDrelated changes, how can we "right the ship" so to speak to provide the most "normal" experience to our students? What efforts are we taking to make sure that any focus does not drift from course content to COVID-19 related trauma/issues? Simply moving to synchronous learning through Zoom sessions does not lead to effective, engaged learning and the participants in this research alluded to this concern. The inability of faculty and students to develop and build honest, trusting relationships for open and critical dialog is hampered in unplanned haphazard online learning (Kulikowski, Przytuła, \& Sułkowski, 2021).

Additionally, students in this research shared difficulty in connecting with instructors and it is essential that we be aware of and spend a more concerted effort as institutions to create open communications regarding expectations, responsibilities, and communication modalities with students to help build community and develop a sense of belongingness. Moreover, the cessation of in-class sessions resulted in lack of motivation for the participants. Another theme emerged that all of us have to grapple with and find solutions for was unsafe/inaccessible home environment and difficulty accessing other learning resources due to various reasons, i.e., addictions, safety, and disability. Support services for students who feel unsafe or are managing disabilities need to be at the forefront of institutional leaders in the digital environment. Smaller group discussions, using breakout sessions, or alternate week sessions, seem to be more 
meaningful for the students as they are able to create a sense of community and belongingness. As observed by the participants in our research, engaging in Zoom discussions with larger groups (full classes) is stress-inducing and confusing for students as it was harder to manage the group and must be avoided at all costs. In light of the above findings, it is recommended that universities consider these concerns as they institutionalize and standardize online education to increase student retention and engagement (Yang \& Huang, 2021).

\section{CONCLUSION AND LIMITATION}

It is imperative that universities work to address the needs of all students as they access education irrespective of challenges in their living spaces. Given the potential for ongoing online learning, considerations need to be made to attend to student safety and ability to effectively learn at home. Such awareness and actions reflect the growing movement for trauma-informed educational practices. The pandemic has negatively affected our collective mental, emotional, and financial wellbeing, increasing anxiety and stress amongst the students. All humanity has been engulfed with losses during the current pandemic, and the students in this research reiterated losses at several levels. Feelings of disorganization, isolation, disconnection from peers and faculty during quarantine, lack of enjoyment, as well cancellations of graduation gatherings and celebrations contributed to exacerbated stress and anxiety for the students. These factors call attention to the need for educators and administrators to consider the social and emotional needs of students which have been compounded by social distancing regulations and to create additional spaces for student connection and support. In addition to focusing on curriculum and strengthening hygiene practices on campus, universities need to incorporate and make freely available online mental health services for all students. Clear management protocols and flowcharts documenting online access to support services should be widely distributed through a variety of mediums to all stakeholders when the majority of the students are learning online (Toquero, 2020). Universities have to be prepared to support the students enduring academic failures (procrastination and reduced motivation) due to collective human suffering caused by the pandemic. University leaders need to cultivate empathy, caring community, and trust amongst faculty, staff, and students as they navigate learning complexities that the pandemic has foisted a very tall order in the world of online education when students face housing, food, and technological insecurities (Evans, 2020).

Data for this web-based qualitative research were completed by students who voluntarily participated in the study and the resulting sample is not a random sample. Secondly, the participating students come from the same university which is characterized as a comprehensive public university situated in a small metropolitan area. Even though the results are not generalizable, they provide important insights for educators and administrators as they plan and develop curriculum, services, and policies that support the learning needs of all the students they serve during the pandemic. Further investigation is needed at a broader scope to further test these emerging observations.

\section{REFERENCES}

Adnan, M., \& Anwar, K. (2020). Online learning amid the COVID-19 pandemic: Students' perspectives. Journal of Pedagogical Sociology and Psychology, 2(1), 45-51. https:// doi.org/10.33902/JPSP.202020261309

Al-Okaily, M., Alqudah, H., Matar, A., Lutfi, A., \& Taamneh, A. (2020). Dataset on the acceptance of e-learning system among universities students' under the COVID-19 pandemic conditions. Data in Brief, 32, 106176-106176. https:/ / doi.org/10.1016/j.dib.2020.106176

Ana, A., Minghat, A. D., Purnawarman, P., Saripudin, S., Muktiarni, M., Dwiyanti, V., \& Mustakim, S. S. (2020). Students' perceptions of the twists and turns of e-learning in the midst of the COVID-19 outbreak. Revista Romaneasca Pentru Educatie Multidimensionala, 12(1), 15-26. https://doi.org/10.18662/rrem/12.1sup2/242 
Aucejo, E. M., French, J., Araya, M. P. U., \& Zafar, B. (2020). The impact of COVID-19 on student experiences and expectations: Evidence from a survey. Journal of Public Economics, 191, 1-15. https://doi.org/10.1016/j.jpubeco.2020.104271

Cao, W., Fang, Z., Hou, G., Han, M., Xu, X., Dong, J., \& Zheng, J. (2020). The psychological impact of COVID-19 epidemic on college students in China. Psychiatry Research, 287, 112934-112934. https://doi.org/10.1016/j.psychres.2020.112934

Chen, R. N., Liang, S. W., Peng, Y., Li, X. G., Chen, J. B., Tang, S. Y., \& Zhao, J. B. (2020). Mental health status and change in living rhythms among college students in China during the COVID-19 pandemic: A large-scale survey. Journal of Psychosomatic Research, 137, 110219. https://doi.org/10.1016/j.jpsychores.2020.110219

Cohen, A. K., Hoyt, L. T., \& Dull, B. (2020). A descriptive study of COVID-19-related experiences and perspectives of a national sample of college students in Spring 2020. The Journal of Adolescent Health: Official Publication of the Society for Adolescent Medicine, 67(3), 369-375. https://doi.org/10.1016/j.jadohealth.2020.06.009

Crawford, J., Butler-Henderson, K., Rudolph, J., Malkawi, B., Glowatz, M., Burton, R., Magni, P. A., \& Lam, S. (2020). COVID-19: 20 countries' higher education intra-period digital pedagogy responses. Journal of Applied Learning $\mathcal{E}$ Teaching, 3(1), 9-28. https://doi.org/10.1680/geot.2008.T.003

De Boer, H. (2021). COVID-19 in Dutch higher education. Studies in Higher Education, 46(1), 96106. https:// doi.org/10.1080/03075079.2020.1859684

Denzin, N. K., \& Lincoln, Y. S. (2011). Introduction: The discipline and practice of qualitative research. In N. K. Denzin \& Y. S. Lincoln (Eds.), The Sage handbook of qualitative research (pp 120). Sage.

Eringfeld, S. (2021). Higher education and its post-coronial future: Utopian hopes and dystopian fears at Cambridge University during COVID-19. Studies in Higher Education, 46(1), 146-157. https://doi.org/10.1080/03075079.2020.1859681

Evans, N. (2020). Leading with empathy: Supporting faculty through COVID-19 and beyond. The Department Chair, 31(1). https:// doi.org/10.1002/dch.30336

Griffiths, J. (2020). E-learning, during the pandemic and beyond. British Journal of Community Nursing, 25(6), 265-265. https:// doi.org/10.12968/bjcn.2020.25.6.265

Hasan, N., \& Bao, Y. (2020). Impact of "e-Learning crack-up" perception on psychological distress among college students during COVID-19 pandemic: A mediating role of "fear of academic year loss". Children and Youth Services Review, 118, 105355. https://doi.org/10.1016/j.childyouth.2020.105355

Hoyt, L. T., Cohen, A. K., Dull, B., Castro, E. M., \& Yazdani, N. (2020). “Constant stress has become the new normal": Stress and anxiety inequalities among U.S. college students in the time of COVID-19. Journal of Adolescent Health, S1054-139X(20), 30646-30647. https://doi.org/10.1016/j.jadohealth.2020.10.030

Jena, P. K. (2020). Impact of COVID-19 on higher education in India. International Journal of Advanced Education and Research (IJAER), 5(3), 77-81.

Kapasia, N., Paul, P., Roy, A., Saha, J., Zaveri, A., Mallick, R., Barman, B., Das, P., \& Chouhan, P. (2020). Impact of lockdown on learning status of undergraduate and postgraduate students during COVID-19 pandemic in West Bengal, India. Children and Youth Services Review, 116, 105194. https:// doi.org/10.1016/j.childyouth.2020.105194

Karademir, A., Yaman, F., and Saatçioğlu, Ö. (2020). Challenges of higher education institutions against COVID-19: The case of Turkey. Journal of Pedagogical Research, 4(4), 453-474. https://doi.org/10.33902/JPR.2020063574

Krippendorff, K. (2019). Content analysis: An introduction to its methodology (4th ed.). Sage.

Kulikowski, K., Przytuła, S., \& Sułkowski, Ł. (2021). E-learning? never again! On the unintended consequences of COVID-19 forced e-learning on academic teacher motivational job characteristics. Higher Education Quarterly, preprint, 1-16. https://doi.org/10.1111/hequ.12314 
Mladenova, T., Kalmukov, Y., \& Valova, I. (2020). Covid 19 - A major cause of digital transformation in education or just an evaluation test. TEM Journal, 9(3), 1163-1170. https:// doi.org/10.18421/TEM93-42

Palgi, Y., Shrira, A., Ring, L., Bodner, E., Avidor, S., Bergman, Y., Cohen-Fridel, S., Keisari, S., \& Hoffman, Y. (2020). The loneliness pandemic: Loneliness and other concomitants of depression, anxiety and their comorbidity during the COVID-19 outbreak. Journal of Affective Disorders, 275, 109-111. https:/ / doi.org/10.1016/j.jad.2020.06.036

Peters, M. A., Rizvi, F., McCulloch, G., Gibbs, P., Gorur, R., Hong, M., . . Misiaszek, L. (2020). Reimagining the new pedagogical possibilities for universities post-covid-19: An EPAT collective project. Educational Philosophy and Theory, 1-44. https://doi.org/10.1080/00131857.2020.1777655

Roy, H., Ray, K., Saha, S., \& Ghosal, A. K. (2020). A study on students' perceptions for online Zoom-app based flipped class sessions on anatomy organised during the lockdown period of COVID-19 epoch. Journal of Clinical $\mathcal{E}$ Diagnostic Research, 14(6), 1-4. https://doi.org/10.7860/JCDR/2020/44869.13797

Rudenstine, S., McNeal, K., Schulder, T., Ettman, C. K., Hernandez, M., Gvozdieva, K., \& Galea, S. (2020). Depression and anxiety during the COVID-19 pandemic in an urban, Low-Income public university sample. Journal of Traumatic Stress. https:// doi.org/10.1002/jts.22600

Sales, D., Cuevas-Cerveró, A., \& Gómez-Hernández, J.-A. 2020. Perspectives on the information and digital competence of Social Sciences students and faculty before and during lockdown due to Covid-19. El Profesional de La Información, 29(4), 1-20. https://doi.org/10.3145/epi.2020.jul.23

Schreier, M. (2012). Qualitative content analysis in practice. Sage.

Shahzad, A., Hassan, R., Aremu, A.Y., Hussain, A., \& Lodhi, R. N. (2020). Effects of COVID-19 in E-learning on higher education institution students: The group comparison between male and female. Quality \& Quantity. https:// doi.org/10.1007/s11135-020-01028-z

Son, C., Hegde, S., Smith, A., Wang, X., \& Sasangohar, F. (2020). Effects of COVID-19 on college students' mental health in the United States: Interview survey study. Journal of Medical Internet Research, 22(9), e21279-e21279. https://doi.org/10.2196/21279

Tesar, M. (2020). Towards a post-COVID-19 'new normality?’: Physical and social distancing, the move to online and higher education. Policy Futures in Education, 18(5), 556-559. https://doi.org/10.1177/1478210320935671

Toquero, C. M. (2020). Challenges and opportunities for higher education amid the COVID-19 pandemic: The Philippine context. Pedagogical Research, 5(4), 1-5. https://doi.org/10.29333/pr/7947

Wang, Z., Yang, H., Yang, Y., Liu, D., Li, Z., Zhang, X., . . Mao, C. (2020). Prevalence of anxiety and depression symptom, and the demands for psychological knowledge and interventions in college students during COVID-19 epidemic: A large cross-sectional study. Journal of Affective Disorders, 275, 188-193. https://doi.org/10.1016/j.jad.2020.06.034

World Health Organization. (2020). WHO Coronavirus (COVID-19) Dashboard. World Health Organization. https:// covid19.who.int/

Yang, B. \& Huang, C. (2021) Turn crisis into opportunity in response to COVID-19: Experiences from a Chinese university and future prospects. Studies in Higher Education, 46(1), 121-132. https://doi.org/10.1080/03075079.2020.1859687 
Impact of Online Education on Student Learning during the Pandemic https://doi.org/10.46627/silet.v2i2.65

Author (s):

${ }^{*}$ Hermeet K. Kohli (Corresponding Author)

School of Social Work,

University of Southern Maine,

Portland, Maine 04105, United States of America

Email: hermeet.kohli@maine.ed

Donna M. Wampole

School of Social Work,

University of Southern Maine,

Portland, Maine 04105, United States of America

Email: donna.wampole@maine.edu

Amarpreet S. Kohli

School of Business,

University of Southern Maine,

Portland, Maine 04105, United States of America

Email: amarpreet.kohli@maine.edu 